C2012, Elsevier. Licensed under the Creative Commons Attribution-NonCommercialNoDerivatives 4.0 International http://creativecommons.org/about/downloads (ब) 


\title{
Cost-exergy optimisation of linear Fresnel reflectors
}

\author{
J. D. Nixon and P. A. Davies*
}

Sustainable Environment Research Group, School of Engineering and Applied Science

Aston University, Aston Triangle, Birmingham, B4 7ET, UK

*corresponding author, e-mail: p.a.davies@aston.ac.uk, Tel +44 1212043724

\begin{abstract}
This paper presents a new method for the optimisation of the mirror element spacing arrangement and operating temperature of linear Fresnel reflectors (LFR). The specific objective is to maximise available power output (i.e. exergy) and operational hours whilst minimising cost. The method is described in detail and compared to an existing design method prominent in the literature. Results are given in terms of the exergy per total mirror area $\left(\mathrm{W} / \mathrm{m}^{2}\right)$ and cost per exergy (US $\left.\$ / \mathrm{W}\right)$. The new method is applied principally to the optimisation of an LFR in Gujarat, India, for which cost data have been gathered. It is recommended to use a spacing arrangement such that the onset of shadowing among mirror elements occurs at a transversal angle of $45^{\circ}$. This results in a cost per exergy of $2.3 \$ / \mathrm{W}$. Compared to the existing design approach, the exergy averaged over the year is increased by $9 \%$ to $50 \mathrm{~W} / \mathrm{m}^{2}$ and an additional 122 hours of operation per year are predicted. The ideal operating temperature at the surface of the absorber tubes is found to be $300^{\circ} \mathrm{C}$. It is concluded that the new method is an improvement over existing techniques and a significant tool for any future design work on LFR systems.
\end{abstract}

Keywords:

Solar thermal collector, Linear Fresnel reflector (LFR), Linear Fresnel collector (LFC), Exergy, CSP. 


\begin{tabular}{|c|c|}
\hline \multicolumn{2}{|c|}{ Nomenclature } \\
\hline$A_{a}$ & Effective mirror aperture area $\left(\mathrm{m}^{2}\right)$ \\
\hline$A_{m}$ & Total mirror area $\left(\mathrm{m}^{2}\right)$ \\
\hline$A_{c g}$ & Surface area of receiver cover glazing $\left(\mathrm{m}^{2}\right)$ \\
\hline$A_{p}$ & Surface area of exposed receiver $\left(\mathrm{m}^{2}\right)$ \\
\hline$A_{r}$ & Area of receiver $\left(\mathrm{m}^{2}\right)$ \\
\hline$d_{n}$ & Width of shade on mirror element (m) \\
\hline$D N I$ & Direct-normal irradiance $\left(\mathrm{W} / \mathrm{m}^{2}\right)$ \\
\hline$E_{x, \text { out }}$ & Exergy per total mirror area $\left(\mathrm{W} / \mathrm{m}^{2}\right)$ \\
\hline$I A M$ & Incident angle modifier (-) \\
\hline$L$ & Length of collector \\
\hline$P_{n}$ & Pitch (m) \\
\hline$Q$ & Net heat transfer to receiver $(\mathrm{W})$ \\
\hline$Q_{I n} *$ & Heat transferred in $(\mathrm{W})$ \\
\hline$Q_{\text {Loss }}$ & Heat loss $(\mathrm{W})$ \\
\hline$Q_{n}$ & Distance of an $\mathrm{n}^{\text {th }}$ mirror element from receiver $(\mathrm{m})$ \\
\hline$S_{n}$ & Shift (m) \\
\hline$T_{a}$ & Ambient temperature $(\mathrm{K})$ \\
\hline$T_{r}$ & Temperature of receiver $(\mathrm{K})$ \\
\hline$T_{r, \max }$ & Stagnation temperature (maximum temperature of receiver) $(\mathrm{K})$ \\
\hline$T_{r, o p t}$ & Optimum temperature of receiver $(\mathrm{K})$ \\
\hline$U_{L}$ & Overall heat transfer coefficient $\left(\mathrm{W} / \mathrm{m}^{2} . \mathrm{K}\right)$ \\
\hline$W$ & Width of mirror element $(\mathrm{m})$ \\
\hline \multicolumn{2}{|c|}{ Greek Symbols } \\
\hline$\alpha$ & Absorption \\
\hline$\alpha_{s}$ & Solar altitude \\
\hline$\beta$ & Ray angle from mirror element to receiver \\
\hline$\gamma_{s}$ & Solar azimuth angle from the south \\
\hline$\delta$ & Declination \\
\hline$\eta_{c}$ & Collector efficiency \\
\hline$\eta_{\text {Carnot }}$ & Carnot efficiency \\
\hline$\eta_{0}$ & Optical efficiency \\
\hline$\eta_{\text {Shadow }}$ & Shadow efficiency \\
\hline$\theta_{l}$ & Angle in the longitudinal plane \\
\hline$\theta_{n}$ & Slope angle of an $\mathrm{n}^{\text {th }}$ mirror element \\
\hline$\theta_{p}$ & Profile angle of the sun \\
\hline$\theta_{t}$ & Angle in the transversal plane \\
\hline$\lambda$ & Intercept factor \\
\hline$\rho$ & Reflectance \\
\hline$\tau$ & Transmittance \\
\hline$\varphi$ & Latitude \\
\hline$\omega$ & Solar hour angle \\
\hline
\end{tabular}




\section{Introduction}

Among solar thermal collectors, the linear Fresnel reflector (LFR), also referred to as the linear Fresnel collector (LFC), is considered a promising technology due to its simple and inexpensive design. It captures, however, less energy that other collectors and this makes it important to seek improvements in performance and further reduction in costs [1-2]. First developed in 1961 by Giorgio Francia, the LFR has received renewed attention over the last few years [3]. One significant recent development has been Puerto Errado 1, the world's first LFR commercial power plant, built in southern Spain. This 1.4 MW power plant commenced selling power to the Spanish grid in March 2009. Construction of Puerto Errado 2, a $30 \mathrm{MW}$ power plant, has also begun in Murcia, Spain [4]. Industrial process heat applications are also a vast but relatively untouched area for concentrating solar power (CSP) technologies. Since 2005 numerous LFR collectors have also been constructed for industrial applications and solar cooling in the European towns of Freiburg, Bergamo, Grombalia, and Sevilla [5] and in various locations across the USA [6]. A large pilot plant demonstrating a LFR was also erected at the Plataforma Solar de Almería (PSA) in Spain and tested until 2008 [7].

The LFR typically uses flat mirror elements of equal width to focus the sun's rays onto a linear central receiver supported by a tower (see Figure 1). A well designed receiver can increase the performance considerably. Several receiver designs exist, with configurations using simple pipes, plates, evacuated tubes and secondary concentrating devices [8]. Typically a horizontal type is favoured over a vertical or angled receiver [9-10]. One particular design often utilized is the trapezoidal cavity receiver which comprises partially insulated absorber pipes with a reflector plate and cover glazing forming a cavity for the collection of rays and minimisation of heat losses [11-12]. Due to its simplicity and low cost, the trapezoidal cavity receiver has been selected for this study.

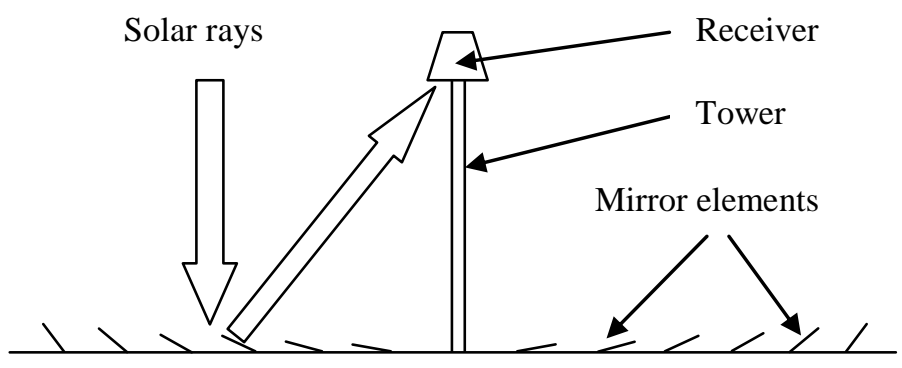

Figure 1: Linear Fresnel reflector with mirror elements directing the sun's rays onto a horizontal receiver.

One particular difficulty with the LFR is shading and blocking caused by adjacent rows of mirrors. Increasing the spacing between mirror rows or the height of the receiver reduces these effects, but can increase cost because more land is required. Land usage may not be an important issue in some situations such as deserts and certain rural areas [13]. However, for solar process heat or solar thermal cooling applications roof installations may be used requiring compact footprint. The design of the width, shape, spacing, and number of mirror elements of the LFR has been studied by several authors and optimised for various applications [10-11, 14-15]. However, those authors chose the spacing arrangement of the mirror elements according to the method by Mathur et al. [16-17]. This method (henceforth referred to concisely as 'Mathur's method') calculates the appropriate value of the shift (i.e. the horizontal gap between adjacent mirror elements) such that shading and blocking of 
reflected rays are avoided at solar noon specifically, thus providing a technical (but not necessarily economic) design principle of the solar collector. Other authors have optimised the equidistant spacing of mirror elements for levelized electricity cost [18-19]. Studies using ray-tracing have also been used to optimise the optical performance of an LFR with equidistant spacing [20-21].

A study of the exergy for an LFR provides a means of analysing the collector's maximum available power, for given operating and ambient temperatures, without the need for a detailed specification of the plant to which the collector is coupled. Achievable performance can then be predicted for a collector with specified location, mirror field arrangement and tracking orientation. Exergetic analyses of solar collectors have already been carried out by several authors. For example, Singh et al. studied the exergetic efficiencies of a solar thermal power plant having parabolic trough collectors coupled to a Rankine cycle, to show that the maximum heat losses occurred at the concentrator-receiver assembly [22]. Tyagi et al. have studied the exergetic performance of a collector as a function of the mass flow rate, concentration ratio and hourly solar irradiation [23]. Gupta and Kaushik investigated different feed water heaters for a direct steam generation solar thermal power plant [24]. Indeed, the exergy concept has been widely adopted for thermodynamic assessment of power generation systems within various fields of the renewable energy sector, ranging from wind power to geothermal power systems, and extended to comparisons of non-renewable energy sources $[13,25-26]$.

The aim here is to present a method to optimise the mirror spacing arrangement of an LFR. The objective of the optimisation is to maximise exergy and operational hours and minimise cost. This will be achieved through analysis of the optics for different non-equidistant spacing arrangements over an annual period, not just at solar noon. By way of example, the method will be applied to the location of Gujarat, India.

\section{Method of optimisation}

The measure of cost to be minimised is the ratio of the capital cost per exergy. The cost estimate will be calculated from the sum of the main components, namely the collector's frame, concentrator, receiver, and land costs. Running costs are neglected because these are considered equivalent among the design variations. Therefore the following expressions are used:

$$
\frac{\text { Cost }}{\text { Exergy }}=\frac{\text { Total Cost Estimate }}{\left.\left[D N I . A_{m} \cdot \eta_{o}(\theta=0) . I A M\right)-Q_{\text {Loss }}\right] \eta_{\text {Carnot }}}
$$

where

Total Cost $=$ Collector Size $($ Frame + Land $)+\left(A_{m}\right.$. Concentrator $)+\left(A_{r}\right.$. Receiever $)$

Exergy is calculated from the direct-normal solar radiation, DNI $\left(\mathrm{W} / \mathrm{m}^{2}\right)$ on the collector's total mirror area, $A_{m}$, and the heat loss from the receiver, $Q_{\text {Loss }}$. The calculation takes into account the terms $\eta_{0}(\theta=0), I A M$, and $\eta_{\text {Carnot }}$ representing the optical efficiency for normal incidence rays to the horizontal, the incidence angle modifier (IAM), which accounts for the losses in the concentrator and receiver optics for varying ray incidence angles, and the Carnot efficiency respectively. Key to this investigation is the shadow efficiency, which is 
incorporated into the IAM, and will depend upon the concentrator's mirror element spacing arrangement. The Carnot efficiency is an idealisation underlying the exergy analysis and is calculated on the assumption that the receiver operates at a constant or continuously optimised surface temperature. Since our focus is on the design of the collector, the variation in temperature of the heat transfer fluid inside the absorber tubes and over the solar field is not considered. This would require detailed assumptions about the plant design (e.g. piping layout, choice of heat transfer fluid, and flow rate) that are beyond the scope of this study.

For a range of different mirror element spacing arrangements, and operating temperatures, the above efficiencies and thus the corresponding exergies are calculated. The spacing arrangements are chosen such that the mirror elements are spaced for the onset of shadowing at a given height of the sun in the sky. This generally leads to non-equidistant spacing with the mirrors further from the tower more widely spaced. The sun's height is represented by the transversal angle which is the angle between the projection of the sun's rays onto a plane perpendicular to the tracking axis and the vertical.

The method comprises four main steps, which are listed below and described more fully subsequently.

1. Determination of solar irradiation characteristics for target location: Calculate typical characteristics of solar radiation for the target location based on a typical meteorological year (TMY).

2. Determine mirror spacing designs and shadow efficiencies: Develop a number of mirror spacing arrangements each for the onset of shadowing at a given transversal angle. Find corresponding hourly shadow efficiencies, for each design.

3. Performance of collector: Analyse heat loss from the receiver. For each spacing arrangement, calculate optical efficiency at normal incidence and hourly values of variables: DNI, IAM (which accounts for shadowing, blocking of reflected rays, incidence cosine for each mirror element, and effective mirror aperture area), heat transfer coefficient, receiver temperature, ambient temperature, Carnot efficiency and thus output exergy averaged over the year. The calculation is repeated for (a) different constant operating temperatures and (b) a continuously optimised operating temperature.

4. Application: For each spacing arrangement determine cost per exergy using Eq.(2.1). Provide optimum design recommendations based on exergy, cost and operational hours.

To study the sensitivity of the optimised design to input parameters in the case study, upper and lower limits are applied to the costs of the mirror elements, the land, and the receiver. Four cost scenarios are considered. (i) a minimum baseline cost, (ii) a high component cost, (iii) a high land cost, and (iv) a high component and land cost.

\subsection{Determination of solar irradiation characteristics for target location}


Hourly direct-normal irradiance (DNI) values are calculated for a TMY in Gujarat using the meteorological database, Meteonorm [27]. The orientation considered in this study is a northsouth horizontal axis with east-west tracking.

\subsection{Determine LFR spacing designs and shadow efficiencies}

The slope angle and distance from the receiver for each mirror element are determined for a given transversal angle. The amount of shadowing that is produced on an hourly basis for each design can then be found. Results for the shadow efficiency for a series of different spacing arrangements, for a typical day of each month, are then produced as a final output. A number of standard calculations relating to the sun-earth geometry are omitted from this description as these are available from the literature [28-29].

\subsubsection{Geometrical positioning of mirror elements}

The sun's position, relative to the axis of rotation of the LFR elements, is determined from the solar profile angle [30].

The profile angle, $\theta_{p}$, in the transversal plane can be found for a north-south tracking axis by,

$\tan \theta_{p}=\frac{\tan \alpha_{s}}{\cos \left(90-\gamma_{s}\right)}$

The projected angle into the longitudinal plane is given by,

$\tan \theta_{l}=\frac{\tan \alpha_{s}}{\cos \gamma_{s}}$

Where, $\alpha_{s}$, is the solar altitude angle, and $\gamma_{s}$ is the solar azimuth angle from the south. The transversal angle, $\theta_{t}$, is then the angle to the vertical i.e. the complement of the profile angle.

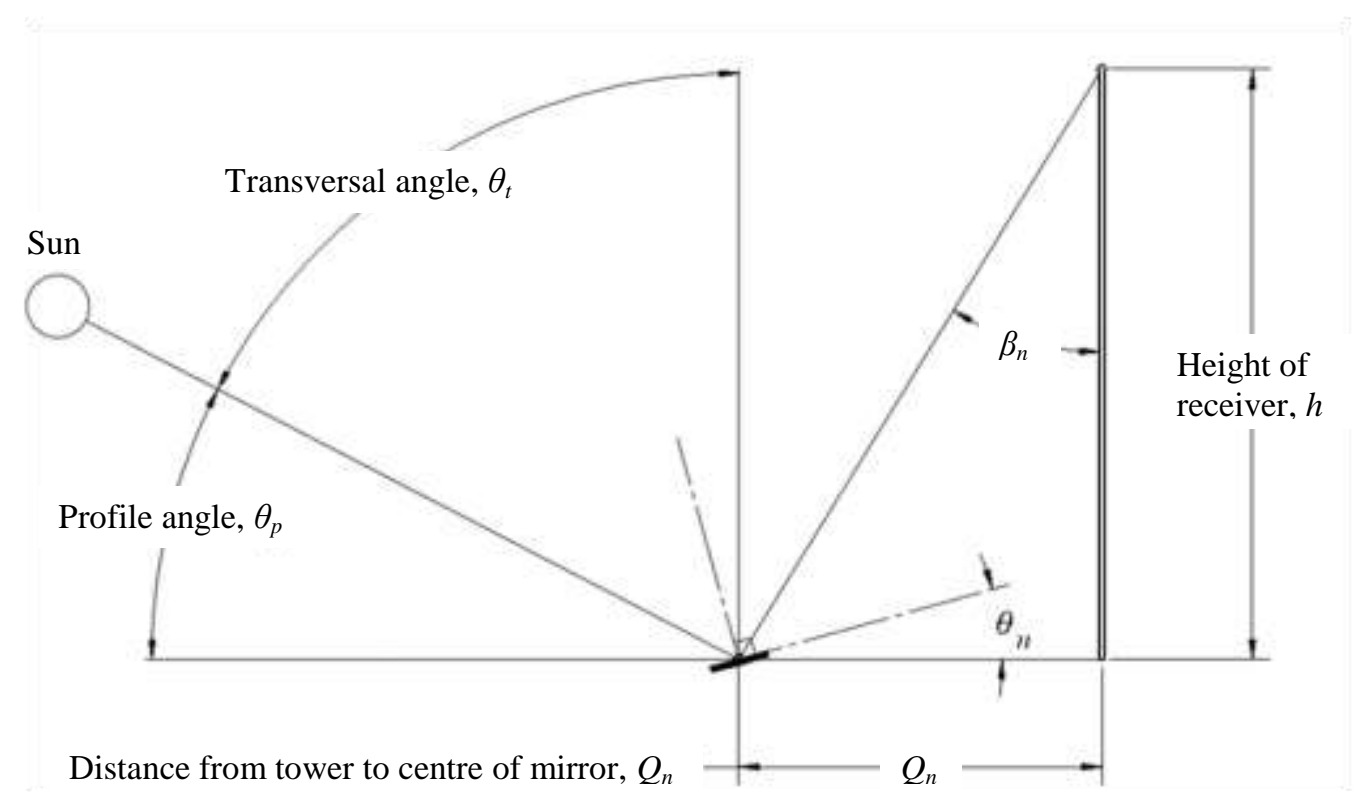

Figure 2: Sun's position relative to an LFR, showing the path of a single ray from a mirror element to a receiver tower. 
The slope angle, $\theta_{n}$, for a mirror element located at a distance $Q_{n}$, from the receiver, can be determined for any profile angle from Eq.(2.5) (see Figure 2). The following equations in this section enable hourly slope angles to be determined for the purpose of specifying the shift distance required for the onset of shadowing at a particular solar profile angle.

$\theta_{n}=\frac{90-\theta_{p}-\beta_{n}}{2}$

Where $\beta$, the angle subtended between the receiver tower and the projection onto the transversal plane of a ray reflected towards the receiver, is given by,

$\tan \beta_{n}=\frac{Q_{n}}{H}$

The first mirror (starting from the centre and working out) is placed such that the receiver does not cast a shadow upon it at midday. The following mirrors are pitched with varying amounts of shift, $S_{n}$, for a given profile angle (see Figure 3).

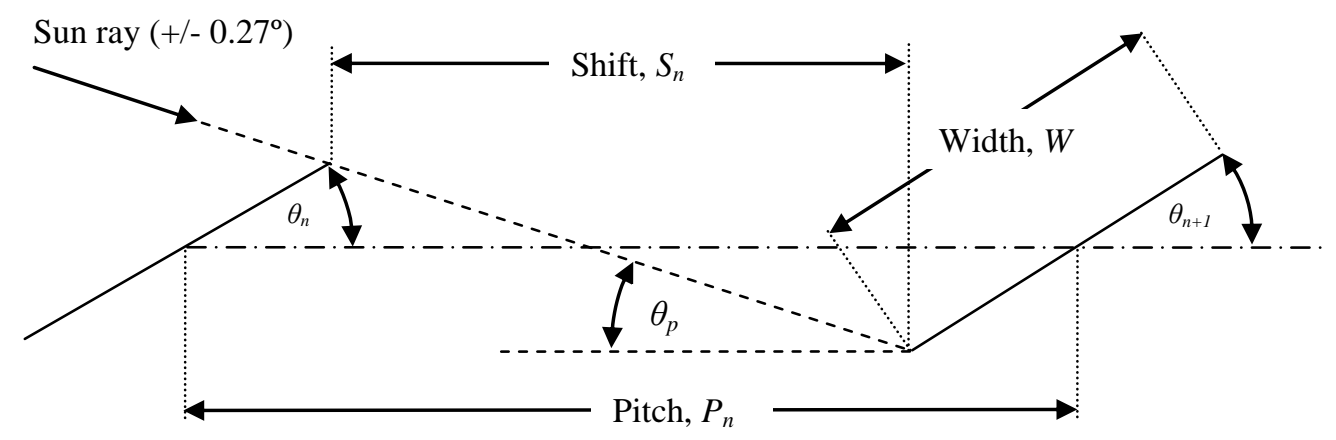

Figure 3: Shift distance between two consecutive mirror elements based on the sun's profile angle.

For a mirror element of width $W$ and pitch $P_{n}$ from its inward neighbour, the shift can be calculated from the following two equations,

$S_{n}=P_{n}-\frac{W}{2}\left(\cos \theta_{n}+\cos \theta_{n+1}\right)$

$S_{n}=\frac{W\left[\sin \theta_{n}+\left(\sin \theta_{n+1}-\sin \theta_{n}\right)\right]}{\tan \left(\theta_{p}-0.27\right)}$

the simultaneous solution of which gives,

$P_{n}=\frac{W\left[\sin \theta_{n}+\left(\sin \theta_{n+1}-\sin \theta_{n}\right)\right]}{\tan \left(\theta_{p}-0.27\right)}+\frac{W}{2}\left(\cos \theta_{n}+\cos \theta_{n+1}\right)$

Because the distance, $Q_{n}$, from a mirror element to the receiver tower changes for each newly selected value of shift, an iterative process is required to provide the final spacing for each 
mirror element. The effective area of aperture, $A_{a}$, of the mirror elements as encountered by approaching rays in the transversal plane can be calculated by,

$A_{a}=\sum_{n=1}^{k} W \cos \left(\theta_{t}-\theta_{n}\right)$

The incidence cosine for an $\mathrm{n}^{\text {th }}$ mirror element in the transversal plane is therefore given by $A_{a n} / W$.

\subsubsection{Shadow on mirror elements}

Until the sun's profile angle reaches that of the design profile angle and corresponding transversal angle used to specify the mirror spacing arrangement, a proportion of the mirror elements will be in the shade. For a spacing arrangement based upon a particular design transversal angle, the average shadowing on the collector system throughout the day can be calculated from the geometry shown in Figure 4.

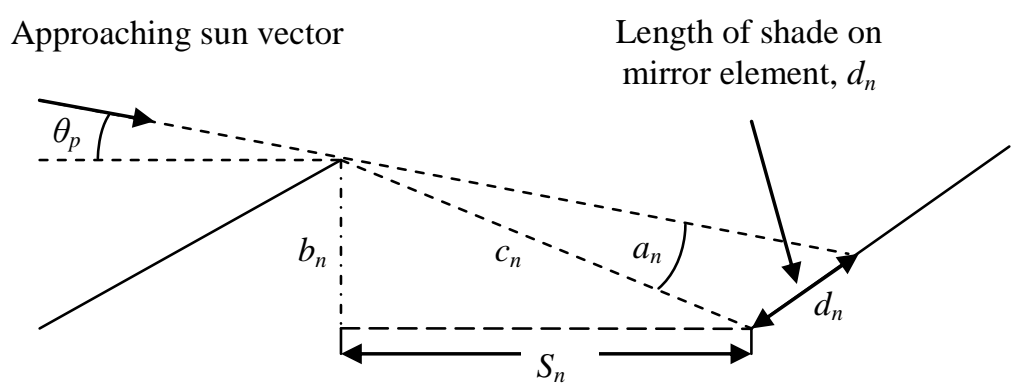

Figure 4: Shadow cast on a mirror element when the sun is lower than the design profile angle.

Using trigonometry, the following equations can be determined,

$b_{n}=\frac{W}{2}\left(\sin \theta_{n}+\sin \theta_{n+1}\right)$

$c_{n}{ }^{2}=b_{n}^{2}+S_{n}^{2}$

$a_{n}=90-\tan ^{-1}\left(S_{n} / b_{n}\right)-\theta_{P}$

$d_{n}=\frac{c_{n} \sin a_{n}}{\sin \left(\theta_{p}+\theta_{n+1}\right)}$

Therefore the shadow efficiency throughout the day, for various spacing arrangements, each based on a different transversal angle, can be found from the amount of shade upon each mirror, $d_{n}$, and the overall width of the mirror element, $W$. The average shadowing on an LFR can therefore be calculated for any time of day.

$\eta_{\text {Shadow }_{n}}=1-\frac{d_{n}}{W}$ 
$\eta_{\text {Shadow }}=\frac{\sum \eta_{\text {Shadow }_{n}}}{n}$

\subsubsection{Selection of spacing arrangements}

Examples of spacing arrangements used for the optimisation are illustrated in Figure 5. Each is labelled $\mathrm{S} 15^{\circ}, \mathrm{S} 30^{\circ}$ etc according to the corresponding transversal angle for the onset of shadowing. The corresponding approximate solar times for shadow free operation are also indicated, though note that these times refer specifically to Gujarat in April and will be different for other locations and times of year.

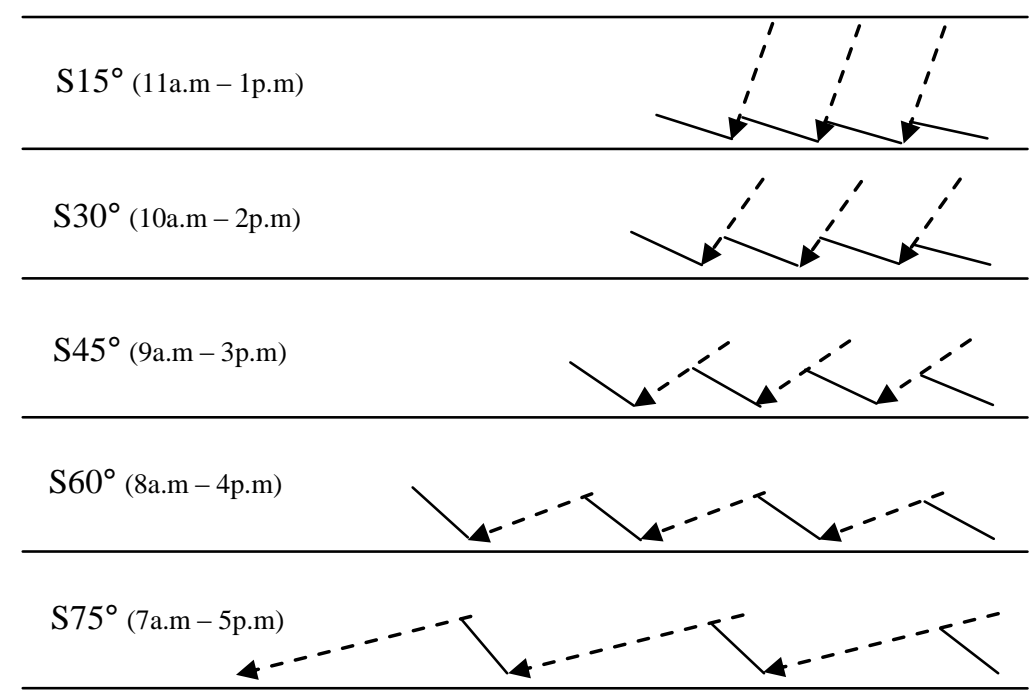

Figure 5: Spacing arrangements set for the onset of shadowing at various transversal angles. Hours of no shadowing are given for the Gujarat area in April.

\subsection{Performance of collector}

The exergy, i.e. maximum available power output in $\mathrm{W} / \mathrm{m}^{2}$ of the collector's total mirror area, for an LFR at a certain hour of the day can be calculated.

$E_{x, \text { out }}=Q\left(1-\frac{T_{a}}{T_{r}}\right)$

Where $Q$, the heat transfer at the receiver at a temperature $T_{r}$ (representing the temperature at the surface of the absorber tubes), is given by,

$Q=Q_{\text {in }}{ }^{*}-Q_{\text {Loss }}$

Where, $Q_{i n} *$ is the product of the direct solar irradiance, total mirror area, optical efficiency at normal incidence and the incidence angle modifier, which includes the effective mirror aperture area and changing optics for ray incidence angles in the transversal and longitudinal planes. 
$Q_{\text {in }}{ }^{*}=D N I \cdot A_{m} \eta_{0}(\theta=0) . I A M$

A thermodynamic study performed on the LFR with a horizontal absorber trapezoidal cavity receiver configuration (see Figure 6), is used to determine an approximation of the heat loss $Q_{\text {Loss. }}$. Note that the cover glazing width is chosen such that a diverging edge ray of the widest mirror element is accepted for a direct beam angle of zero.

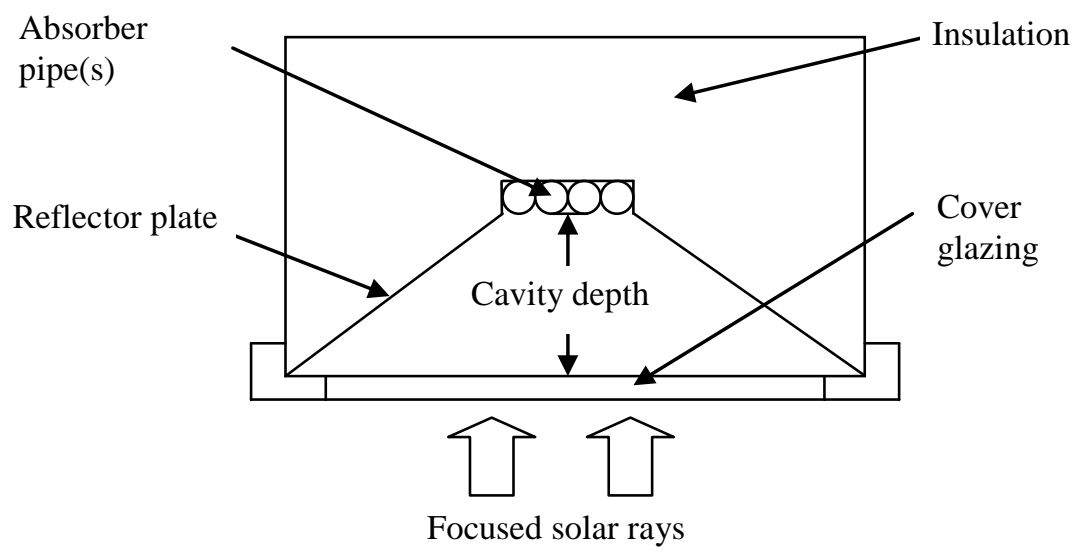

Figure 6: Schematics of a trapezoidal cavity receiver.

Singh et al. have shown that the overall heat transfer coefficient, $U_{L}$, is a summation of the heat loss coefficients from the bottom of the receiver through convection and radiation, and the heat loss coefficient from the insulated sides for a trapezoidal receiver [31].

For a receiver of given characteristics, the heat transfer coefficient can be plotted against the receiver temperature. The example plot of Figure 7 shows that the heat transfer coefficient increases significantly with temperature. The heat loss coefficient is used to determine the stagnation temperature, $T_{r, \max }$, which occurs when all incoming solar radiation is lost as ambient heat, meaning no more heat transfer can take place at the receiver.

$T_{r, \max }=T_{a}+\frac{D N I \cdot \eta_{0}(\theta=0) \cdot I A M \cdot A_{m}}{U_{L} A_{r}}$

Optical efficiency is an essential parameter for the calculation of exergy and stagnation temperature in any solar collector. The optical efficiency of the system includes factors such as the reflectance, $\rho$, the transmittance of the cover, $\tau$, the absorbance, $\alpha$, and the intercept factor, $\lambda$. The absorbed solar radiation is also decreased if shading and blocking is caused from adjacent mirror elements. Estimations can be made for the optical efficiency on an hourly basis using an incident angle modifier (IAM). Asymmetric solar collectors with translational symmetry show a bi-axial dependency with respect to the direct beam incidence angle [30]. A bi-axial incident angle modifier includes a transversal angle, $\theta_{t}$, (for rays perpendicular to the rotation axis of the concentrator elements) and a longitudinal angle $\theta_{l}$ (for rays in a plane parallel to the rotation axis) [32]. The IAM is defined by the ratio of the collector output at a given incidence angle $\eta_{0}(\theta)$ and the collector output at normal incidence $\eta_{0}(\theta=0)$. 
$\operatorname{IAM}(\theta)=\frac{\eta_{0}(\theta)}{\eta_{0}(\theta=0)}$

The approach taken in this study is to project the solar incidence angle onto the transversal and longitudinal plane to calculate a total optical efficiency based on a product of the $\operatorname{IAM}\left(\theta_{t}\right)$ and $\operatorname{IAM}\left(\theta_{l}\right)$. For an LFR, depending on the spacing arrangement of the mirror elements, the effective mirror aperture area, individual mirror incidence cosines, blocking of reflected rays and shadowing show a large dependency on $\theta_{t}$. In the longitudinal plane the major effects are the transmittance of a cover or glazing, the intercept factor, and the absorption and reflectance of the collector in respect to a changing $\theta_{l}$. Assuming the collector is of substantial length the end losses for rays with a shallow $\theta_{l}$ are neglected.

Ray-tracing is commonly employed in the analysis of the optical efficiency for solar collectors and is used in this study. Due to the width of the solar disk, as observed from the collector, solar rays diverge with an angle of $+/-0.27^{\circ}$. Buie and Monger have studied circumsolar radiation and its effect on LFR optics [33]. The amount of circumsolar radiation varies considerably according to atmospheric conditions. For the sake of generality it is neglected from this analysis. Additional divergence from tracking inaccuracies and mirror shape surface errors are also not considered. The reflectivity of the mirrors is taken to be constant and the relationship between absorption and angle of incidence is as given by Tesfamichael and Wäckelgård for nickel pigmented aluminium oxide $\left(\mathrm{Ni}^{-} \mathrm{Al}_{2} \mathrm{O}_{3}\right)$ [34].

Determination of the optical efficiency now enables the stagnation temperature to be calculated. A linear approximation of the heat transfer coefficient (see Figure 7) can be used to derive an expression for $T_{r, \max }$, by substitution from Eq.(2.20). Therefore a solution for $T_{r, \max }$ is obtained on an hourly basis. Furthermore, the optimum operating temperature of the receiver, $T_{r, \text { opt }}$, can be deduced [13].

$T_{r, \text { opt }}=\sqrt{T_{r, \max } T_{a}}$

In reality constant temperature operation is more practical. If the stagnation temperature is below the target operational temperature it is assumed that any captured radiation is not utilized, as the irradiance level are not sufficient for the collector to operate.

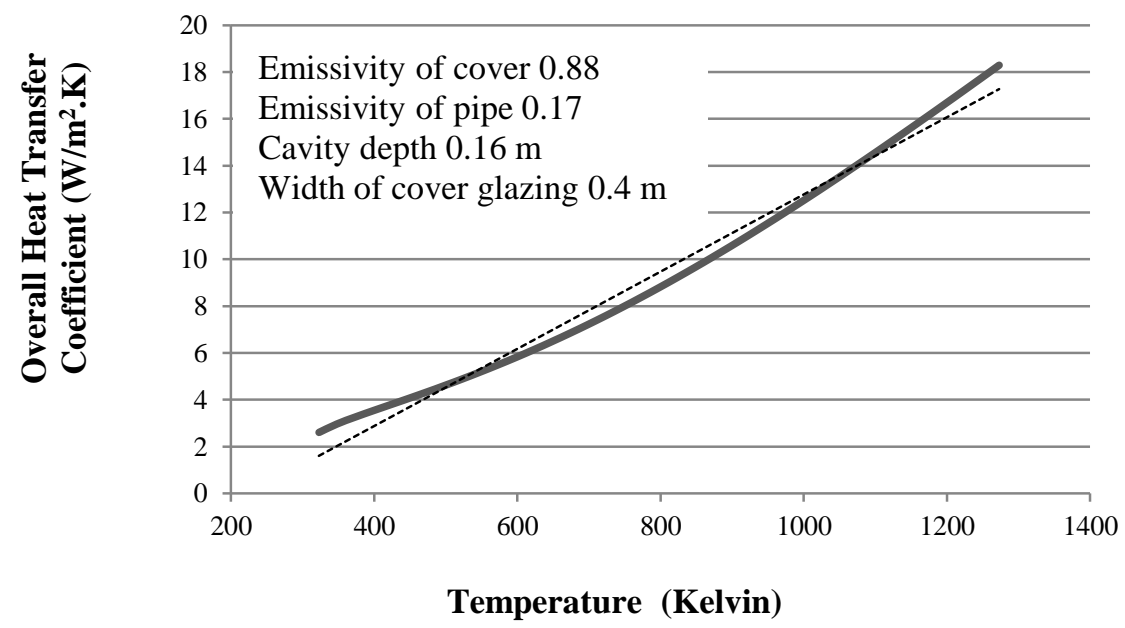

Figure 7: The heat loss coefficient increases with the trapezoidal cavity receiver temperature and may be approximated by a linear trend. 


\subsection{Application to case study}

The cost-exergy method is now applied to an LFR prototype, operating with different spacing arrangements and a north-south tracking axis, in the Gujarat area. To research costs, the authors constructed a prototype LFR in Vapi, Gujarat, thus enabling them to gather the relevant data. To account for likely variations, four cost scenarios are considered (see section 2). Units of US dollars are used here, converted from Indian national rupees (INR) at 2011 rates (see Table 1).

Table 1: Initial upper and lower cost estimates of a prototype LFR and land costs for Gujarat.

\begin{tabular}{ccccccc}
$\begin{array}{c}\text { Horizontal } \\
\text { Frame }\end{array}$ & $\begin{array}{c}\text { Lower } \\
\text { Concentrator }\end{array}$ & $\begin{array}{c}\text { Upper } \\
\text { Concentrator }\end{array}$ & Lower Land & Upper Land & $\begin{array}{c}\text { Lower } \\
\text { Receiver }\end{array}$ & $\begin{array}{c}\text { Upper } \\
\text { Receiver }\end{array}$ \\
\hline $750 \mathrm{Rs} . / \mathrm{m}^{2}$ & $2953 \mathrm{Rs} . \mathrm{m}^{2}$ & $10000 \mathrm{Rs} . \mathrm{m}^{2}$ & $720 \mathrm{Rs} . / \mathrm{m}^{2}$ & $10000 \mathrm{Rs} . / \mathrm{m}^{2}$ & $2000 \mathrm{Rs} . / \mathrm{m}^{2}$ & $8000 \mathrm{Rs} . \mathrm{m}^{2}$ \\
\hline $16 \$ / \mathrm{m}^{2}$ & $63 \$ / \mathrm{m}^{2}$ & $214 \$ / \mathrm{m}^{2}$ & $15 \$ / \mathrm{m}^{2}$ & $214 \$ / \mathrm{m}^{2}$ & $43 \$ / \mathrm{m}^{2}$ & $171 \$ / \mathrm{m}^{2}$ \\
\hline
\end{tabular}

The prototype LFR consisted of twenty eight $80 \mathrm{~mm}$ wide mirrors, and a $100 \mathrm{~mm}$ wide receiver fixed at a height of 2 metres. The receiver was formed from four $25 \mathrm{~mm}$ diameter copper tubes joined together, held in a $200 \mathrm{~mm}$ wide and $160 \mathrm{~mm}$ deep trapezoidal cavity. The design parameters of the different spacing arrangements for the collector are given in Table 2.

Table 2: Sizing parameters of each spacing arrangement for the prototype LFR.

\begin{tabular}{ccccc}
$\begin{array}{c}\text { Spacing } \\
\text { arrangement }\end{array}$ & $\begin{array}{c}\text { Area of receiver per } \\
\text { unit length }\left(A_{r} / L\right)\end{array}$ & $\begin{array}{c}\text { Area of mirror per } \\
\text { unit length }\left(A_{m} / L\right)\end{array}$ & $\begin{array}{c}\text { Total width of } \\
\text { collector }(m)\end{array}$ & $\begin{array}{c}\text { Area of cover glazing per } \\
\text { unit length }\left(A_{c g} / L\right)\end{array}$ \\
\hline Mathur & 0.1 & 2.24 & 2.69 & 0.32 \\
$\mathrm{~S} 15^{\circ}$ & 0.1 & 2.24 & 2.62 & 0.32 \\
$\mathrm{~S} 30^{\circ}$ & 0.1 & 2.24 & 2.90 & 0.34 \\
$\mathrm{~S} 45^{\circ}$ & 0.1 & 2.24 & 3.46 & 0.40 \\
$\mathrm{~S} 60^{\circ}$ & 0.1 & 2.24 & 4.75 & 0.52 \\
$\mathrm{~S} 75^{\circ}$ & 0.1 & 2.24 & 9.08 & 0.96 \\
\hline
\end{tabular}

To obtain the optical efficiency at normal incidence $(\theta=0)$ and the incident angle modifiers $\operatorname{IAM}\left(\theta_{t}\right)$ and $\operatorname{IAM}\left(\theta_{l}\right)$ for the collector, ray-tracing was performed using Optica, a software package developed within Mathematica ${ }^{\circledR}$. The $\operatorname{IAM}\left(\theta_{t}\right)$ and $\operatorname{IAM}\left(\theta_{l}\right)$ for each spacing arrangement is shown in Figure 8 and 9. Mathur's method for determining the spacing arrangement of the mirror elements was also analysed to enable a comparison of the methods to be drawn. 


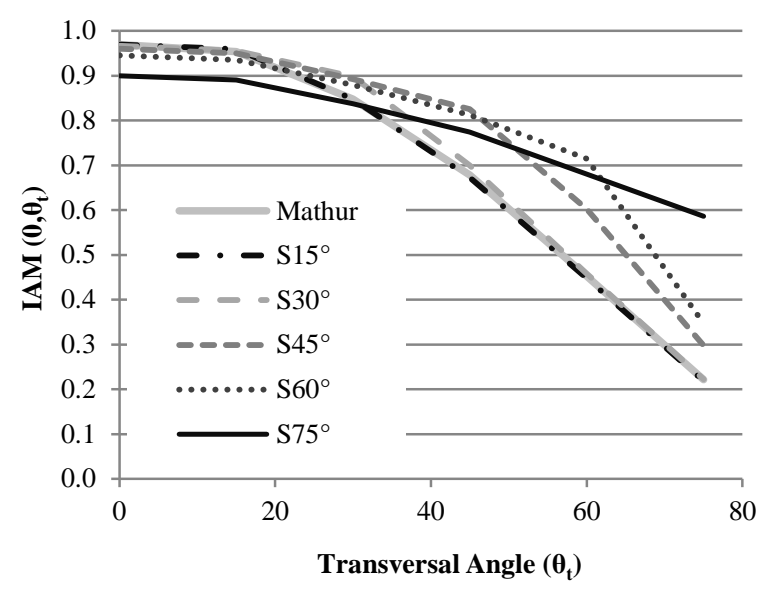

Figure 8: IAM for changing angles in the transversal plane for each spacing arrangement.

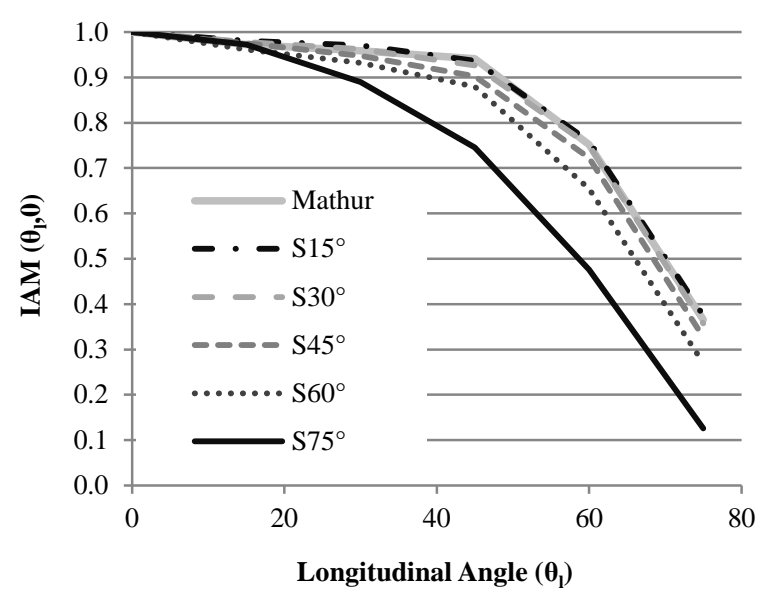

Figure 9: IAM for changing angles in the longitudinal plane for each spacing arrangement.

The exergy outputs per total mirror area (given as an hourly average over a TMY) at different operating temperatures for each spacing arrangement are shown in Figure 10. Maximum exergy of $50 \mathrm{~W} / \mathrm{m}^{2}$ is achieved with $\mathrm{S} 52.5^{\circ}$ (i.e. corresponding to a transversal angle of $52.5^{\circ}$ for the onset of shadowing) and a constant operating temperature of $300^{\circ} \mathrm{C}$; the baseline cost per exergy at this temperature is also plotted in Figure 10. A continuously optimised temperature gives only slightly higher exergy of $52 \mathrm{~W} / \mathrm{m}^{2}$. As a spacing of $\mathrm{S} 52.5^{\circ}$ maximises exergy and is also close to the optimum for minimum cost it is therefore also analysed in addition to those specified in Figure 5. Figure 11 shows that for a constant operating temperature of $300^{\circ} \mathrm{C}$ the operational hours are maximised at $\mathrm{S}^{\circ} 5^{\circ}$ and that for lower operating temperatures the number of operational hours per year are comparatively insensitive to the choice of spacing arrangement. 


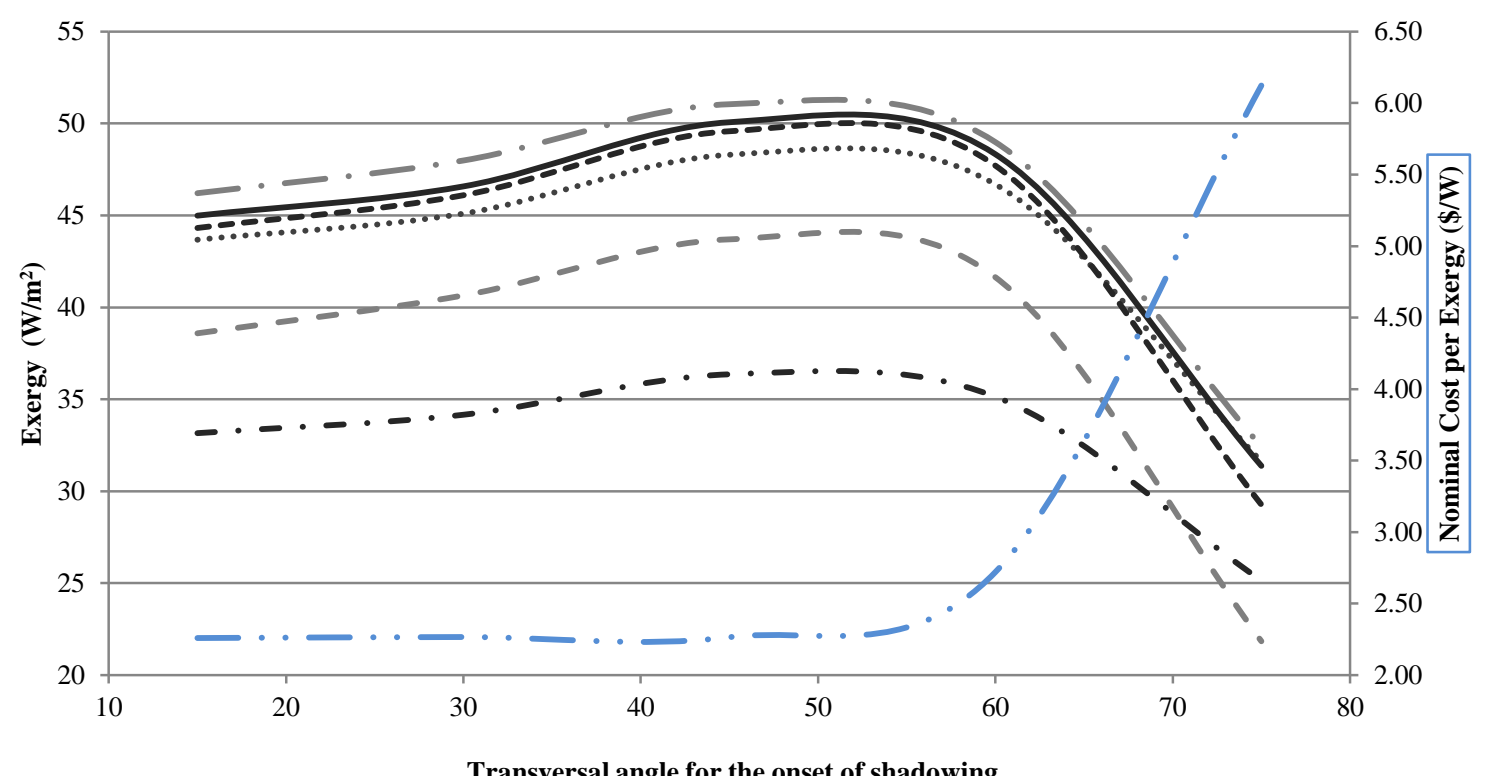

Transversal angle for the onset of shadowing

- $150^{\circ} \mathrm{C} \cdots \cdots \cdot 250^{\circ} \mathrm{C} \longrightarrow 300^{\circ} \mathrm{C}---350^{\circ} \mathrm{C}-250^{\circ} \mathrm{C} \longrightarrow$ Opt Temp $\longrightarrow$ Nominal Cost $(\$ / \mathrm{W})$

Figure 10: Exergy averaged over the TMY vs. spacing arrangement as specified by the transversal angle used for the onset of shadowing (Figure 3.6), for different operating temperatures and for the ideal case of continuously optimised temperature. The baseline cost per exergy for $300{ }^{\circ} \mathrm{C}$ operation is plotted on a secondary axis.

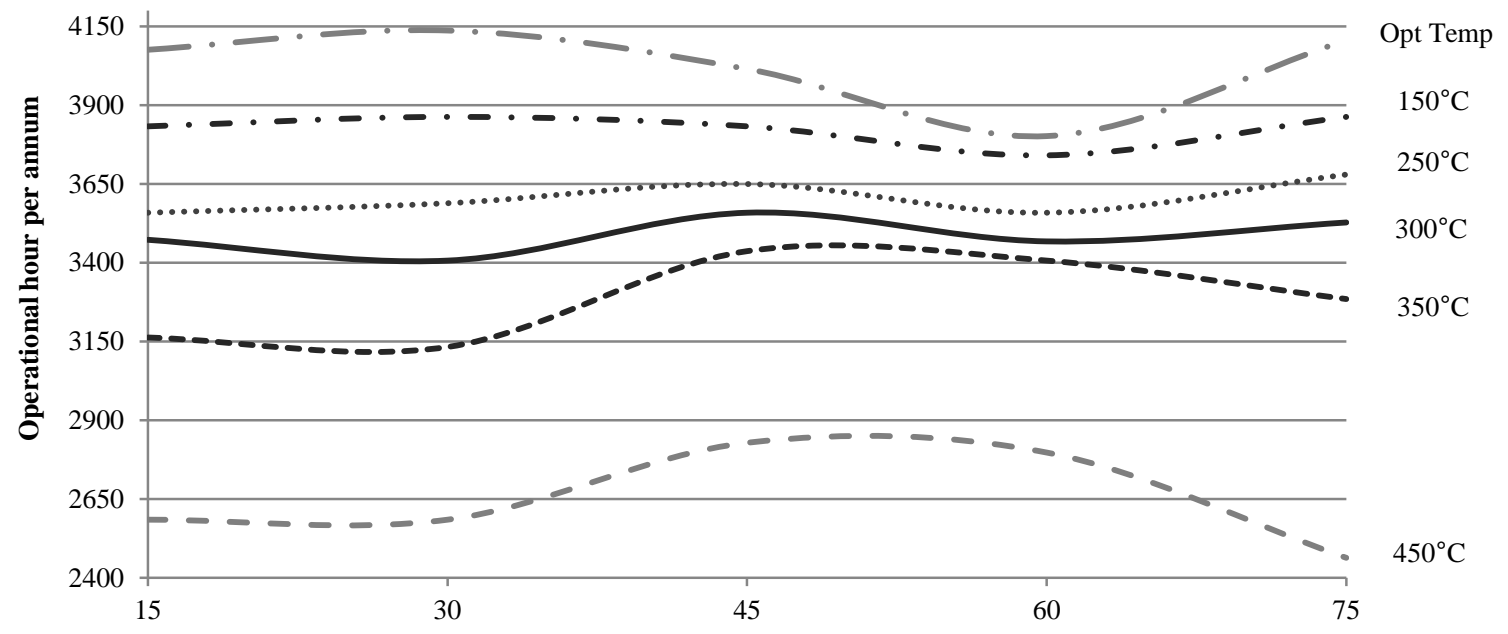

Transversal angle for the onset of shadowing

Figure 11: Operational hours per annum vs. spacing arrangement as specified by the transversal angle used for the onset of shadowing (Figure 3.6), for different operating temperatures and for the ideal case of continuously optimised temperature, $T_{r, o p t}$.

To show the sensitivity to cost assumptions, Table 3 presents for each spacing arrangement the cost-exergy calculations for the four cost scenarios of the sensitivity analysis, at the preferred operating temperature of $300^{\circ} \mathrm{C}$. Included among the spacing arrangements are 
S52.5 ${ }^{\circ}$ and Mathur for comparison. Table 4 shows yearly exergy and net heat transfer to the receiver.

Table 3: Cost-exergy results for the four cost sensitivity scenarios for the different spacing arrangements, operating with a north-south axis tracking orientation.

\begin{tabular}{|c|c|c|c|c|c|c|c|}
\hline \multirow{2}{*}{$\begin{array}{c}\text { Spacing } \\
\text { arrangement }\end{array}$} & \multirow{2}{*}{$\begin{array}{c}\text { Optical } \\
\text { efficiency } \\
\eta(\theta=0)\end{array}$} & \multirow{2}{*}{$\begin{array}{c}\text { Exergy per } \\
\text { total mirror } \\
\text { area } \\
\left(\mathrm{W} / \mathrm{m}^{2}\right)\end{array}$} & \multirow{2}{*}{$\begin{array}{l}\text { Operational } \\
\text { hours per } \\
\text { annum }\end{array}$} & \multicolumn{4}{|c|}{ Sensitivity Analysis $(\$ / W)$} \\
\hline & & & & $\begin{array}{c}\text { Baseline } \\
\text { cost }\end{array}$ & $\begin{array}{c}\text { High } \\
\text { component } \\
\text { cost }\end{array}$ & $\begin{array}{l}\text { High } \\
\text { land } \\
\text { cost }\end{array}$ & $\begin{array}{c}\text { High } \\
\text { component } \\
\text { and land cost }\end{array}$ \\
\hline Mathur & $83.6 \%$ & 45.9 & 3437 & 2.2 & 5.6 & 7.4 & 10.8 \\
\hline $\mathrm{S} 15^{\circ}$ & $81.7 \%$ & 45.0 & 3473 & 2.3 & 5.4 & 7.4 & 10.9 \\
\hline $\mathrm{S} 30^{\circ}$ & $83.1 \%$ & 46.6 & 3407 & 2.3 & 5.2 & 7.8 & 11.1 \\
\hline $\mathrm{S} 45^{\circ}$ & $83.1 \%$ & 50.1 & 3559 & 2.3 & 5.0 & 8.4 & 11.5 \\
\hline $\mathrm{S} 52.5^{\circ}$ & $82.3 \%$ & 50.1 & 3559 & 2.4 & 5.0 & 9.4 & 12.5 \\
\hline $\mathrm{S} 60^{\circ}$ & $81.7 \%$ & 48.3 & 3468 & 2.7 & 5.4 & 11.4 & 14.6 \\
\hline $\mathrm{S} 75^{\circ}$ & $66.1 \%$ & 31.4 & 3528 & 6.1 & 9.3 & 31.7 & 36.7 \\
\hline
\end{tabular}

Table 4: Annual exergy produced and net heat transfer to receiver.

\begin{tabular}{ccccc}
\multirow{2}{*}{$\begin{array}{c}\text { Spacing } \\
\text { arrangement }\end{array}$} & $\begin{array}{c}\text { Exergy per } \\
\text { unit length }\end{array}$ & $\begin{array}{c}\text { Exergy per total } \\
\text { mirror area }\end{array}$ & $\begin{array}{c}\text { Net heat transfer per } \\
\text { unit length }\end{array}$ & $\begin{array}{c}\text { Net heat transfer per } \\
\text { total mirror area }\end{array}$ \\
\cline { 2 - 5 } $\mathrm{kWh} / \mathrm{m} \mathrm{a}$ & $\mathrm{kWh} / \mathrm{m}^{2} \mathrm{a}$ & $\mathrm{kWh} / \mathrm{m} \mathrm{a}$ & $\mathrm{kWh} / \mathrm{m}^{2} \mathrm{a}$ \\
\hline Mathur & 901 & 402 & 1916 & 855 \\
$\mathrm{~S} 15^{\circ}$ & 883 & 394 & 1878 & 838 \\
$\mathrm{~S} 30^{\circ}$ & 914 & 408 & 1945 & 868 \\
$\mathrm{~S}^{\circ}$ & 982 & 439 & 2090 & 933 \\
$\mathrm{~S}^{\circ} 5^{\circ}$ & 983 & 439 & 2088 & 932 \\
$\mathrm{~S}^{\circ}$ & 948 & 423 & 2017 & 900 \\
$\mathrm{~S}^{\circ}$ & 616 & 275 & 1313 & 586 \\
\hline
\end{tabular}

\section{Discussion}

Based on the case study, the recommended spacing arrangement is that corresponding to an onset of shadowing at a transversal angle of $45^{\circ}$. Using this arrangement, the exergy, and number of operational hours per year are maximised, and the cost per exergy is kept at a minimum for all cost scenarios. In comparison to the method of Mathur et al., a $9 \%$ increase in exergy was achieved, resulting in an extra 122 hours of operation per annum at a receiver temperature of $300^{\circ} \mathrm{C}$. This is consistent with operating fluid temperatures claimed for commercial LFRs given that the temperature used in this study is the absorber tube surface temperature and therefore expected to be slightly higher than the fluid temperatures $[4,8]$. For different operating temperatures the exergy output and operational hours varied, yet the optimum spacing arrangement remained constant. A constant receiver temperature of $300^{\circ} \mathrm{C}$ proved to be the most efficient operating temperature for the prototype LFR presented. If a coupled heat cycle could utilize a continuously changing optimum operating temperature the operational hours would be significantly increased by $13 \%$; however, the exergy would not improve significantly compared to a constant operating temperature of $300^{\circ} \mathrm{C}$. 
The sensitivity analysis established that the cost is relatively insensitive to spacing arrangements specified by a traversal angle of up to $52.5^{\circ}$ for a baseline cost scenario. The optimum spacing arrangement for a high component cost is always the one giving maximum exergy, because this maximises the output from potentially expensive materials. A maximum saving of $11 \%$ in the cost per exergy was obtained under this scenario. On the other hand, the narrower spacing arrangements use less land and are thus favoured when land costs are high. Therefore, it is recommended that for a ground installation with plentiful land and an application requiring high operating temperatures for long periods of time, such as for electricity generation, the spacing arrangement giving maximum exergy should be selected. For an application with restricted space or high land cost, such as a roof installation, a narrower spacing arrangement, as given by Mathur's method, should be used.

The cost-exergy approach has proven to be a more illuminating (albeit more complex) method compared to that of Mathur et al. when it comes to specifying the spacing arrangement of the mirror elements in an LFR system. The new method can in fact be used to provide alternative recommendations for different LFR designs to reduce land usage, increase performance or minimise cost according to the priorities at hand. A potential drawback of the approach is that it leads to bespoke design recommendations according to location. Moreover, the non-uniform spacing may make the support frame more complex to design and manufacture. The improved performance should justify to some extent these additional investments, even if the cost advantages alone are not sufficient. Whereas it is unlikely that the LFR would be redesigned for each individual location, the flexibility of modern manufacturing techniques and the growth in demand for solar collectors should partially overcome these drawbacks and justify a number of design variants each optimised for a climatic or economic region.

Avoidance of excessive mirror reflector spacing in an LFR has been shown to be important so that optical performance is not compromised and cost from additional array structure and land usage does not become excessive. More factors could be considered in future studies, such as ground preparation, additional steam line length, thermal losses and additional optical effects (e.g. circumsolar radiation, tracking errors, and mirror shape surface errors). These factors could affect the results for the costs and ideal operating temperature. The effects of thermal storage on the potential work output and operational hours could also be considered. The optimisation method outlined in this paper could even be extended to LFRs utilizing different concentrator-receiver assembly configurations. For example, curved mirror elements, which reduce the flux distribution on the absorber and allow wider mirror elements, could be analysed. So could evacuated tube type collectors, which would reduce the heat transfer coefficient, increasing the temperatures and hence exergy of the system. The higher cost of the evacuated tubes would tend to favour optimisation for performance as in the high component cost scenario considered above. A relatively new and exciting variant is the compact linear Fresnel reflector (CLFR), which should also be investigated by extension of the new method.

A limitation of the exergy approach is that it assumes the idealised Carnot engine. It does not take into account losses in real engines or losses associated with extracting the heat from the receiver field using a working fluid. Depending upon the heat cycle coupled to the system, the operational hours at full load would be significantly less than the total operational hours stated in this paper. Nevertheless, the cost-exergy method enables us to arrive at general conclusions without reference to specific applications. For real arrangements the optimum design is likely to be similar even if the overall power output is lower. 


\section{Conclusion}

The cost exergy approach presented in this paper has successfully enabled the spacing arrangement in an LFR to be specified such that the exergy and operational hours are maximised over a typical meteorological year and costs are minimised. For the case study of the LFR situated in Gujarat, it is recommended to use a north-south tracking axis with a nonequidistant spacing arrangement chosen for the onset of shadowing at a transversal angle of $45^{\circ}$, operating at a constant receiver temperature of $300^{\circ} \mathrm{C}$, representing the temperature at the surface of the absorber tubes. This resulted in an additional 122 operational hours per annum being achievable at a baseline cost per exergy of $2.3 \$ / \mathrm{W}$. However, the sensitivity analysis has shown that an increase in the land cost favours a narrower spacing arrangement.

The new method for optimising mirror spacing arrangements can be applied to other locations and is expected to give similarly significant improvements in the value of the LFR for use in a variety of applications.

\section{Acknowledgements}

The authors would like to acknowledge the financial support under the Science Bridge project financed by Research Councils UK (EP/G039992/1) and Department of Science and Technology, India, along with the contributions of colleagues at IIT Delhi and Industrial Boilers Ltd.

\section{References}

[1] International Energy Agency (IEA), Solar Power and Chemical Energy Systems, C. Richter (Ed.) SolarPACES Annual Report, 2009.

[2] J.D. Nixon., P. Davies, P. Dey, Which is the best solar thermal collection technology for electricity generation in north-west India? Evaluation of options using the Analytical Hierarchy Process, Energy, 35 (2010) 5230-5240.

[3] D. Mills, Advances in solar thermal electricity technology, Solar Energy, 76 (2003) 1931.

[4] Novatec Biosol, available at: www.novatecsolar.com, accessed $4^{\text {th }}$ July 2011.

[5] International Energy Agency (IEA), Solar Power and Chemical Energy Systems, C. Richter (Ed.) SolarPACES Annual Report, 2008.

[6] HelioDynamics, available at: www.heliodynamics.com, accessed 13th Sep 2010.

[7] Plataforma Solar de Almería (P.S.A), in: Annual Report, 2007.

[8] D. Feuermann, J. Gordon, Analysis of a two-stage linear Fresnel reflector solar concentrator, Journal of Solar Energy Engineering, 113 (1991) 272.

[9] D. Mills, G. Morrison, Compact linear Fresnel reflector solar thermal powerplants, Solar Energy, 68 (2000) 263-283.

[10] P.L. Singh, R.M. Sarviya, J.L. Bhagoria, Thermal performance of linear Fresnel reflecting solar concentrator with trapezoidal cavity absorbers, Applied Energy, 87 (2010) 541-550.

[11] P. Singh, S. Ganesan, G. Yadav, Technical note-Performance study of a linear Fresnel concentrating solar device, Renewable Energy, 18 (1999) 409-416.

[12] J. Facão, A.C. Oliveira, Numerical simulation of a trapezoidal cavity receiver for a linear Fresnel solar collector concentrator, Renewable Energy, 36 (2011) 90-96.

[13] S.A. Kalogirou, Solar thermal collectors and applications, Progress in Energy and Combustion Science, 30 (2004) 231-295. 
[14] G.D. Sootha, B.S. Negi, A comparative study of optical designs and solar flux concentrating characteristics of a linear fresnel reflector solar concentrator with tubular absorber, Solar Energy Materials and Solar Cells, 32 (1994) 169-186.

[15] N. Velázquez, O. García-Valladares, D. Sauceda, R. Beltrán, Numerical simulation of a Linear Fresnel Reflector Concentrator used as direct generator in a Solar-GAX cycle, Energy Conversion and Management, 51 (2010) 434-445.

[16] S. Mathur, T. Kandpal, B. Negi, Optical design and concentration characteristics of linear Fresnel reflector solar concentrators--II. Mirror elements of equal width, Energy Conversion and Management, 31 (1991) 221-232.

[17] S. Mathur, B. Negi, T. Kandpal, Geometrical designs and performance analysis of a linear fresnel reflector solar concentrator with a flat horizontal absorber, International Journal of Energy Research, 14 (2007) 107-124.

[18] A. Häberle, Geometry optimization of Fresnel-collectors with economic assessment, EuroSun, 2004, Freiburg, Germany.

[19] G. Morin, W. Platzer, M. Strelow, R. Leithner, Techno-Economic System Simulation and Optimisation of Solar Thermal Power Plants, in: SolarPaces, 2008.

[20] G. Barale, A. Heimsath, P. Nitz, A. Toro, Optical Design of a Linear Fresnel Collector for Sicily, SolarPACES, 2010, Perpignan, France.

[21] A. Häberle, C. Zahler, H. Lerchenmüller, M. Mertins, C. Wittwer, F. Trieb, J. Dersch, The Solarmundo line focussing Fresnel collector. Optical and thermal performance and cost calculations, SolarPACES, 2002, Zurich, Switzerland.

[22] N. Singh, S. Kaushik, R. Misra, Exergetic analysis of a solar thermal power system, Renewable Energy, 19 (2000) 135-143.

[23] S.K. Tyagi, S. Wang, M.K. Singhal, S.C. Kaushik, S.R. Park, Exergy analysis and parametric study of concentrating type solar collectors, International Journal of Thermal Sciences, 46 (2007) 1304-1310.

[24] M.K. Gupta, S.C. Kaushik, Exergy analysis and investigation for various feed water heaters of direct steam generation solar-thermal power plant, Renewable Energy, 35 (2010) 1228-1235.

[25] C. Koroneos, T. Spachos, N. Moussiopoulos, Exergy analysis of renewable energy sources, Renewable Energy, 28 (2003) 295-310.

[26] I. Dincer, M.A. Rosen, Exergy analysis of renewable energy systems, in: EXERGY, Elsevier, Amsterdam, 2007, pp. 163-228.

[27] Meteotest, Meteonorm, available at: www.meteonorm.com, accessed 8th Nov 2010.

[28] B. William, S. Geyer, M. Geyer, Power from the Sun, 2001.

[29] T. Muneer, C. Gueymard, H. Kambezidis, Solar radiation and daylight models, Elsevier Butterworth Heinemann, Amsterdam; Boston; London, 2004.

[30] J.A. Duffie, W.A. Beckman, Solar engineering of thermal processes, 3rd ed., John Wiley \& Sons, New York, 2006.

[31] P.L. Singh, R.M. Sarviya, J.L. Bhagoria, Heat loss study of trapezoidal cavity absorbers for linear solar concentrating collector, Energy Conversion and Management, 51 (2010) 329337.

[32] W.R. McIntire, Factored approximations for biaxial incident angle modifiers, Solar Energy, 29 (1982) 315-322.

[33] D. Buie, A.G. Monger, The effect of circumsolar radiation on a solar concentrating system, Solar Energy, 76 (2001) 181-185.

[34] T. Tesfamichael, E. Wäckelgård, Angular solar absorptance and incident angle modifier of selective absorbers for solar thermal collectors, Solar Energy, 68 (2000) 335-341. 


\section{Figure and table legends}

Figure 1: Linear Fresnel reflector with mirror elements directing the sun's rays onto a horizontal receiver.

Figure 2: Sun's position relative to an LFR, showing the path of a single ray from a mirror element to a receiver tower.

Figure 3: Shift distance between two consecutive mirror elements based on sun's profile angle

Figure 4: Shadow cast on a mirror element when the sun is lower than the design profile angle.

Figure 5: Spacing arrangements set for the onset of shadowing at various transversal angles. Hours of no shadowing are given for the Gujarat area in April.

Figure 6: Schematics of a trapezoidal cavity receiver.

Figure 7: The overall heat transfer coefficient increases with the trapezoidal cavity receiver temperature and may be approximated by a linear trend.

Figure 8: IAM for changing angles in the transversal plane for each spacing arrangement.

Figure 9: IAM for changing angles in the longitudinal plane for each spacing arrangement.

Figure 10: Exergy averaged over the TMY vs. spacing arrangement as specified by the transversal angle used for the onset of shadowing (Figure 5), for different operating temperatures and for the ideal case of continuously optimised temperature, $T_{r}$. The baseline cost per exergy for $300^{\circ} \mathrm{C}$ operation is plotted on a secondary axis.

Figure 11: Operational hours per annum vs. spacing arrangement as specified by the transversal angle used for the onset of shadowing (Figure 5), for different operating temperatures and for the ideal case of continuously optimised temperature, $T_{r}$.

Table 1: Initial upper and lower cost estimates of a prototype LFR and land costs for Gujarat. Conversion rate to dollars used is also provided.

Table 2: Sizing parameters of each spacing arrangement for the prototype LFR.

Table 3: Cost-exergy results for the four cost sensitivity scenarios for the different spacing arrangements, operating with a north-south axis tracking orientation.

Table 4: Annual exergy produced and net heat transfer to receiver. 